\title{
Development of an Experimental Rig for Investigation of Higher Order Modes in Ducts
}

\author{
Carl H. Gerhold \\ Senior Research Engineer \\ Associate Fellow, AIAA \\ phone: (757) 864-5279 \\ carl.h.gerhold@nasa.gov
}

\author{
Randolph H. Cabell \\ Research Engineer \\ phone: (757) 864-5266 \\ randolph.h.cabell@nasa.gov \\ NASA Langley Research Center \\ Hampton, Virginia 23668
}

\author{
Martha C. Brown \\ Aerospace Technologist \\ phone: (757) 864-6277 \\ martha.c.brown@nasa.gov
}

\begin{abstract}
Continued progress to reduce fan noise emission from high bypass ratio engine ducts in aircraft increasingly relies on accurate description of the sound propagation in the duct. A project has been undertaken at NASA Langley Research Center to investigate the propagation of higher order modes in ducts with flow. This is a two-pronged approach, including development of analytic models (the subject of a separate paper) and installation of a laboratory-quality test rig. The purposes of the rig are to validate the analytical models and to evaluate novel duct acoustic liner concepts, both passive and active. The dimensions of the experimental rig test section scale to between $25 \%$ and $50 \%$ of the aft bypass ducts of most modern engines. The duct is of rectangular cross section so as to provide flexibility to design and fabricate test duct liner samples. The test section can accommodate flow paths that are straight through or offset from inlet to discharge, the latter design allowing investigation of the effect of curvature on sound propagation and duct liner performance. The maximum air flow rate through the duct is Mach 0.3. Sound in the duct is generated by an array of 16 high-intensity acoustic drivers. The signals to the loudspeaker array are generated by a multi-input/multi-output feedforward control system that has been developed for this project. The sound is sampled by arrays of flush-mounted microphones and a modal decomposition is performed at the frequency of sound generation. The data acquisition system consists of two arrays of flush-mounted microphones, one upstream of the test section and one downstream. The data are used to determine parameters such as the overall insertion loss of the test section treatment as well as the effect of the treatment on a modal basis such as mode scattering. The methodology used for modal decomposition is described, as is a description of the mode generation control system. Data are presented which demonstrate the performance of the controller to generate the desired mode while suppressing all other cut on modes in the duct.
\end{abstract}




\section{Nomenclature}

$p=$ acoustic pressure $(\mathrm{Pa})$

$S P L=$ Sound Pressure Level re $20 \mu \mathrm{Pa}$

$k=\frac{\omega}{c}$

$c=$ speed of sound in air $(\mathrm{m} / \mathrm{s})$

$\rho=$ density of air $\left(\mathrm{kg} / \mathrm{m}^{3}\right)$

$U=$ axial flow speed $(\mathrm{m} / \mathrm{s})$

$\omega=$ circular frequency $(\mathrm{rad} / \mathrm{s})$

$\omega_{c o}=$ frequency at which a mode cuts on

$k_{x}=\frac{n \pi}{a}$

$k_{y}=\frac{m \pi}{b}$

$k_{c o}=$ wavenumber at which a mode cuts on $=\frac{\omega_{c o}}{c}$

$a=$ duct width (m)

$b=$ duct height $(\mathrm{m})$

$k_{z}^{+}=$wavenumber of positive traveling wave $(\mathrm{rad} / \mathrm{m})$

$k_{z}^{-}=$axial wavenumber of negative traveling wave $(\mathrm{rad} / \mathrm{m})$

$\mathrm{A}_{\mathrm{mn}}^{+}=$Amplitude of positive traveling $(\mathrm{m}, \mathrm{n})$ mode $(\mathrm{Pa})$

$\mathrm{A}_{\mathrm{mn}}^{-}=$Amplitude of negative traveling $(\mathrm{m}, \mathrm{n})$ mode $(\mathrm{Pa})$

$\mathrm{T}_{\mathrm{lmn}}^{+}=$Modal transfer function for positive traveling $(\mathrm{m}, \mathrm{n})$ mode at $l^{\text {th }}$ microphone location

$\mathrm{T}_{\mathrm{lmn}}^{-}=$Modal transfer function for negative traveling $(\mathrm{m}, \mathrm{n})$ mode at $l^{\text {th }}$ microphone location

$e=$ rms error of estimated sound distribution at microphone array

$N_{\text {mic }}=$ number of microphones in array

$$
\begin{aligned}
& k_{x y}=\sqrt{k_{x}^{2}+k_{y}^{2}} \\
& M_{o}=\frac{U}{C}
\end{aligned}
$$

$\{\mathrm{A}\}=$ Mode amplitude vector

$[\mathrm{T}]=$ Mode transfer matrix

\section{Introduction}

Significant progress has been made over the past 30 years in reducing the noise generated by aircraft and the consequent impact of aircraft noise on humans. A major contribution to engine noise reduction is the use of a high bypass ratio powerplant, in which the turbojet is used to drive a large ducted fan that provides the majority of engine thrust. Such a high bypass ratio engine, in addition to being more efficient than a pure jet, greatly reduces jet noise as an environmental noise pollutant. The fan is the major noise source in most flight regimes, which source includes broadband noise and coherent noise in tones at the blade passage frequency and its harmonics. The tonal component of the noise is generated by interaction of the rotor wakes with downstream obstructions, such as struts or fan exit guide vanes, and propagates in modes defined by the relative number of blades and obstructions. ${ }^{1,2}$

Because of the importance of the tonal component of fan noise, much work has been devoted to studying the generation and propagation of fan tones in a duct. Heidmann, et $\mathrm{al}^{3}$ performed an experiment in which a number of uniformly-spaced obstructions were placed in the duct upstream of the rotor in order to generate a specific mode structure in the engine inlet. Rice, et $\mathrm{al}^{4}$ showed that the modal structure of the sound in the duct also determines the directivity of far field noise propagation; and Thomas, et $\mathrm{al}^{5}$ demonstrated that the far field noise radiation can be used to estimate the modal structure in the duct. Various methods to measure noise in the engine and decompose it into the modal structure have been developed; including a rotating rake of microphones ${ }^{6}$, surface-mounted microphones in the inlet ${ }^{7}$, or a duct extension. ${ }^{8}$ Heidelberg, et $\mathrm{l}^{9}$ investigated the effect that modeshape has on acoustic performance of a liner. They found that the liner performance improves significantly near a mode cut on.

As noise reduction technologies become incorporated into airplanes, the demand for more sophisticated technologies grows. Evaluation of these new technologies on full scale aircraft is costly; and analytic models, while steadily improving in accuracy, have not yet reached the level where they can reliably predict noise control performance in actual flight conditions. Laboratory ducts are often used to characterize and parameterize sound propagation in and radiation from ducts ${ }^{10,11,12}$ or to assess the performance of noise control treatments. ${ }^{13,14,15}$ However, a search of available duct facilities, undertaken at the beginning of the project, revealed significant drawbacks to these existing facilities: many of the facilities were not open to outside researchers; their designs were not flexible enough to accommodate different duct acoustic treatment 
configurations; the structure of the sound field either was not controlled or was limited to plane waves. Thus the decision was made to develop a test rig in house at NASA Langley Research Center.

The Curved Duct Test Rig (CDTR) is a research tool whose purpose is to improve the understanding of the behavior of duct treatment in a curved duct, such as the aft bypass duct. The bypass duct flow path is often curved to accommodate the engine core, and the CDTR is designed to address the effect of curvature on sound propagation, with the aim of determining whether use can be made of curvature to enhance liner performance. The test section cross-section is rectangular, rather than annular, in order to facilitate the design and manufacture of candidate duct liner configurations. Because of the similarity of the modal sound distribution between the bifurcated annular duct (typical of an aft bypass duct) and the rectangular ducts, it is felt that the results obtained in the rectangular cross section duct can provide data that are applicable to engine installations. The experimental rig is relatively large, the test section dimensions are scaled to between 25 and $50 \%$ of the bypass duct of most modern engines. Air flow through the duct is designed to be typical of bypass duct flow. It is expected that the experimental facility will provide data that validate duct noise control techniques and that can be used to enhance the capability of the analytic models to estimate noise reduction.

Many applications of control systems in ducts have been developed to reduce the tonal noise caused by interaction of rotor wakes and obstructions, either at the source of generation ${ }^{16,17,18}$ or within the duct along the propagation path. These latter applications used secondary sources (loudspeakers) to simulate and control the interaction noise. Thomas, et $\mathrm{al}^{19}$ utilized a time-domain controller, while Gerhold ${ }^{20}$ developed a controller in the frequency domain. Smith, et $\mathrm{al}^{21}$ discuss the use of multiple circumferential arrays of loudspeakers to control radial as well as circumferential modes. In the current application, the goal is not to cancel fan noise but to provide a known, controllable source for fundamental duct propagation and treatment experiments. The control system is designed to generate arbitrary combinations of duct modes at a specified frequency. Similar research was conducted in a spinning mode synthesizer, which utilized an array of circumferentially-mounted loudspeakers in a $0.305 \mathrm{~m}$ diameter duct as described by Palumbo. ${ }^{22}$ The control sources (loudspeakers) in the spinning mode synthesizer were distributed circumferentially at one axial station and specified duct modes were obtained in the duct by controlling the amplitudes and phases to the loudspeakers. This arrangement permitted high controllability of the circumferential modes but compromised controllability of the radial modes. In the current application, an adaptive feedforward control system is used to drive a single mode in a rectangular duct at a specified frequency, and to suppress other modes that are cut on at that frequency. The control sources are distributed on all four sides of the duct at two axial locations, so that control is achieved in both cross dimensions of the duct.

\section{Theoretical Development}

The expression for sound propagation in the duct is derived in this section and then used to derive the methodology for decomposing the measured sound into its modal components.

\section{A. Propagation of sound in a rectangular duct with flow.}

The wave equation is written for a rectangular duct, which is shown schematically in Figure 1 . The flow in the axial direction is assumed to be uniform. The wave equation for the sound pressure can be written in rectangular coordinates as: ${ }^{23}$

$$
\frac{1}{c^{2}}\left(\frac{\partial p}{\partial t}+U \frac{\partial p}{\partial z}\right)^{2}=\frac{\partial^{2} p}{\partial x^{2}}+\frac{\partial^{2} p}{\partial y^{2}}+\frac{\partial^{2} p}{\partial z^{2}}
$$

Assuming $U$ is constant, the sound pressure in the duct due a tone of frequency $\omega$ can be expressed as:

$$
p(x, y, z)=\sum_{m=0}^{\infty} \sum_{n=0}^{\infty} \Psi_{m n}(x, y)\left(A_{m n}^{+} e^{i k_{z}^{+} z}+A_{m n}^{-} e^{i k_{z}^{-} z}\right)
$$

where:

$\Psi_{m n}(x, y)=\cos \left(\frac{m \pi}{b} y\right) \cos \left(\frac{n \pi}{a} x\right)$

$m, n=$ integers 


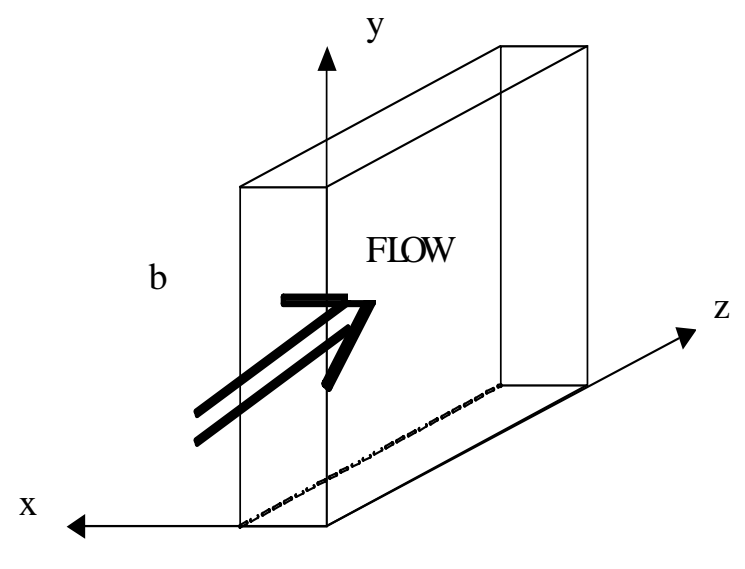

a

Figure 1. Schematic representation of rectangular duct with uniform flow.

The amplitude $A_{m n}^{+}$refers to the positive-traveling wave that goes with the flow and $A_{m n}^{-}$refers to the negative-traveling wave that goes against the flow. The positive-traveling wave is incident in this application, and the negative-traveling wave is reflected. The axial wavenumber, $k_{z}^{+/-}$is defined for the positive or negative traveling waves as:

where:

$$
k_{z}^{+/-}=\frac{k M_{o} m \sqrt{k^{2}-\left(1-M_{o}^{2}\right) k_{x y}^{2}}}{\left(1-M_{o}^{2}\right)}
$$

$\mathrm{k}_{\mathrm{xy}}=\sqrt{\left(\frac{m \pi}{b}\right)^{2}+\left(\frac{n \pi}{a}\right)^{2}}$

By the convention adopted for this derivation, the axial wavenumber for the positive-traveling wave, $k_{z}^{+}<0$, and the negative-traveling wavenumber, $k_{z}^{-}>0$. In addition, the axial wavenumber of the $(\mathrm{m}, \mathrm{n})$ mode must be real in order for sound in that mode to propagate without decay in the duct.

The lowest frequency that meets both criteria, $k_{z}^{+}<0$ and $k_{z}^{+}$real, is defined as the cut off condition for positive-traveling waves in the $(m, n)$ mode:

$$
\omega_{c o}^{+}=c k_{c o}^{+}=c \pi \sqrt{\left(\frac{m^{2}}{b^{2}}+\frac{n^{2}}{a^{2}}\right)}
$$

The wavenumber $k_{z}^{-}$is always greater than 0 by definition, so the cut-off condition for negativetraveling waves in the $(m, n)$ mode is:

$$
\omega_{c o}^{-}=c k_{c o}^{-}=c \pi \sqrt{\left(1-M_{o}^{2}\right)\left(\frac{m^{2}}{b^{2}}+\frac{n^{2}}{a^{2}}\right)}
$$
waves.

In the absence of flow, the cut off conditions are the same for both positive- and negative-traveling

The modes at frequencies below cut on decay exponentially as they progress from the source and are termed evanescent.

\section{B. Estimating the modal content of sound measured in the duct}


The sound at a fixed frequency $\omega$ is measured at $\mathrm{L}$ locations on the walls of the duct. Each term is expressed as a complex-valued pressure. The vector of sound pressures is related to the modal amplitudes of the sound in the duct by the expression:

$$
\left\{\begin{array}{c}
p_{1}\left(x_{1}, y_{1}, z_{1}\right) \\
\bullet \\
p_{l}\left(x_{l}, y_{l}, z_{l}\right) \\
\bullet \\
p_{L}\left(x_{L}, y_{L}, z_{L}\right)
\end{array}\right\}=\left[\begin{array}{cccccccccc}
T_{100}^{+} & \bullet & T_{1 m n}^{+} & \bullet & T_{1 M N}^{+} & T_{100}^{-} & \bullet & T_{1 m n}^{-} & \bullet & T_{1 M N}^{-} \\
\bullet & \bullet & \bullet & \bullet & \bullet & \bullet & \bullet & \bullet & \bullet & \bullet \\
T_{l 00}^{+} & \bullet & T_{l m}^{+} & \bullet & T_{l M N}^{+} & T_{100}^{-} & \bullet & T_{l m n}^{-} & \bullet & T_{l M N}^{-} \\
\bullet & \bullet & \bullet & \bullet & \bullet & \bullet & \bullet & \bullet & \bullet & \bullet \\
T_{L 00}^{+} & \bullet & T_{L m n}^{+} & \bullet & T_{L M N}^{+} & T_{L 00}^{-} & \bullet & T_{L m n}^{-} & \bullet & T_{L M N}^{-}
\end{array}\right]\left\{\begin{array}{c}
A_{00}^{+} \\
\bullet \\
A_{m n}^{+} \\
\bullet \\
A_{M N}^{+} \\
A_{00}^{-} \\
\bullet \\
A_{m n}^{-} \\
\bullet \\
A_{M N}^{-}
\end{array}\right\}
$$

where, for any mode $(\mathrm{m}, \mathrm{n})$ at a location $\left(x_{l}, y_{l}, z_{l}\right)$, the modal response terms of the propagating modes are :

$T_{l m n}^{+}=\Psi_{m n}\left(x_{l}, y_{l}\right) e^{i k_{z m n}^{+} z_{l}}$

and

$T_{l m n}^{-}=\Psi_{m n}\left(x_{l}, y_{l}\right) e^{i k_{z m n}^{-} z_{l}}$

and the modal response terms of evanescent modes are :

$T_{l m n}^{+}=\Psi_{m n}\left(x_{l}, y_{l}\right) e^{-\left|k_{z m n}^{+} z_{l}\right|}$

$T_{l m n}^{-}=\Psi_{m n}\left(x_{l}, y_{l}\right) e^{-\left|k_{z m n}^{-} z_{l}\right|}$

The modal response matrix, $\mathrm{T}$, can be calculated at any frequency and mode, using the known coordinates of the L sound measurement locations. Given L measured pressures, the modal amplitudes for the upstream- and downstream-traveling waves can be determined using the expression:

$$
\{A\}=\left[T^{T} T\right]^{1} T^{T}\{p\}
$$

An important consideration in the application of equation 6 is the number and placement of microphones that are required to produce accurate estimates of the modal amplitudes. A complete analysis is beyond the scope of the present paper, but implicit in equation 6 are the assumptions that modes not included in the matrix $\mathrm{T}$ are either close to orthogonal to the modes that are included, or are of such small amplitude as to be negligible. These assumptions are reasonable at low frequencies, but become less realistic at higher frequencies, as the number of cuton modes approaches the number of microphones, $\mathrm{L}$.

\section{Sound Control System}

An adaptive feedforward control system is used to create a desired sound field in the duct at a single frequency. The control system uses a block adaptive version of the common multiple-error filtered-X LMS algorithm $^{24}$ to compute the inputs to sixteen loudspeakers to create the sound field. The loudspeaker inputs are amplitude and phase-shifted versions of a single frequency reference signal generated by the control system. Responses of 31 wall-mounted microphones close to the sound source provide error feedback for the control algorithm.

\section{A. Control Algorithm}

In several previous duct noise control experiments ${ }^{19,20,21}$, an adaptive feedforward control algorithm was used to minimize acoustic energy in a duct due to an undesirable noise source. In the current application, the same type of control algorithm is used to drive measured wall pressures to a distribution corresponding to a specified hard-wall cut on duct mode at the test frequency. A frequency, mode, and amplitude are specified by the user; and knowing the sensitivity of each microphone, the desired response at each microphone can be 
estimated from equation 2. The phase of the mode is arbitrarily assumed to be zero at the entrance plane to the microphone array. The control algorithm adapts the loudspeaker inputs to minimize the mean square value of the difference between desired microphone responses and actual microphone responses.

The filtered-X LMS algorithm requires a model of the frequency response from each loudspeaker to each microphone at the selected operating frequency. At a single frequency and for a single speakermicrophone pair, this model can be represented by a complex number describing the amplitude and phase shift from loudspeaker input to microphone response. The set of complex values relating each speaker to each microphone are assembled into a $31 \times 16$ transfer function matrix. These values are measured before the control system is turned on in a procedure commonly referred to as system identification. The amplitude and phase relationship depends on conditions in the duct such as temperature and flow speed, so system identification should be done at conditions representative of those present when the control system will be turned on.

The control system was designed and implemented using Simulink and the xPC real-time control platform from the Mathworks. A sample rate of $12.8 \mathrm{kHz}$ was selected based on the hardware resources and a desired maximum mode generation frequency of $2500 \mathrm{~Hz}$. To reduce the computational burden of the algorithm, a block adaptive filtered-X LMS algorithm was implemented. This version buffers a 32-sample frame, or block, of data at $12.8 \mathrm{kHz}$ and averages the weight update across that sample frame for an effective weight update rate of $400 \mathrm{~Hz}$. Although the updates are averaged across a frame of data, the block adaptive algorithm converges more slowly than a non-block adaptive version. ${ }^{25}$

The control system is poorly conditioned across a relatively wide range of frequencies, which necessitated the use of a control effort penalty to avoid overdriving the loudspeakers. In the context of the filtered-X LMS algorithm, conditioning refers to the ratio of the largest to smallest singular value of the transfer function matrix at a single frequency, where poor conditioning is associated with a large condition number. At low frequencies, the sound field in the duct is nearly completely determined by a small number of duct modes traveling in the upstream and downstream directions. For example, below the cut-on of the first cross duct mode, the microphone responses are nearly completely determined by the amplitudes of the upstream and downstream traveling plane wave. Because the control system has excess degrees of freedom at these low frequencies (i.e., more loudspeakers than cut-on modes), the condition number of the transfer function matrix is high. This has negative consequences that include increased convergence time and very large loudspeaker input levels.

One approach to mitigate the affects of poor conditioning is to include a control effort penalty. ${ }^{26} \mathrm{~A}$ control effort penalty causes the optimum solution to be a tradeoff between minimizing the error at the microphones and minimizing the loudspeaker power requirement. For a poorly conditioned control system, a small effort penalty can keep the loudspeaker inputs within in a reasonable range and still achieve accurate reproduction of the desired sound field in the duct. In the current controller, the control effort penalty was implemented using an automatic feedback loop that increased the effort penalty as the loudspeaker inputs approached a pre-specified limiting value. This value was pre-specified to avoid overdriving the loudspeakers.

\section{B. Microphone Locations}

The control system uses an array of microphones flush-mounted on the walls of the duct as error sensors for adjusting the inputs to the loudspeakers. The microphone array must be capable of resolving all cut on modes within the expected operational bandwidth of the test rig (400-2500 Hz). In order to simplify the microphone placement problem, a combinatorial optimization procedure was used. ${ }^{27}$

The goal of the optimization procedure was to select, from a much larger candidate set, a subset of microphones that optimizes a goodness metric. The goodness metric used here is defined as the condition number of the modal response matrix, $\mathrm{T}$ (equation 6) at the highest expected operating frequency. A metric based on condition number was chosen because it not only ensures that each cut on mode is detectable by the microphone array, but also ensures some degree of insensitivity to random noise in the microphone measurements. Specifically, the sensitivity of the solution for the modal amplitude vector, $A_{m n}$, to noise in the sound pressure measurements can be directly related to the condition number of $\mathrm{T} .^{28}$ An array of microphones with low condition number will have less sensitivity to random measurement noise that an array with high condition number.

An analysis indicated that ensuring a low condition number at the highest operating frequency would produce well-conditioned modal response matrices at all lower frequencies (except very near the cut on 
frequency of a mode, where the upstream and downstream traveling waves are indistinguishable from one another).

The particular search procedure used here is known as tabu search. ${ }^{29}$ Tabu search takes an initial microphone subset, randomly selected from the candidate set, and iteratively tries to improve the performance of that subset by swapping in microphones from the candidate set. The swapping is done deterministically, and the algorithm incorporates a history of previously tried solutions. The algorithm also incorporates methods to avoid getting trapped in local minima.

Candidate microphone locations were defined by regularly gridded locations on all four walls of the duct over a $0.305 \mathrm{~m}$ axial span. Because the modal response matrix, $\mathrm{T}$, can be computed using equation 6 , the optimization was done using analytically generated data, rather than experimentally measured values.

\section{Description of the Test Duct}

The test rig is an experimental facility that features large physical scale (25 to $50 \%$ of the size of conventional aft bypass duct), high mean flow (up to Mach 0.3 ), and sound generation with user-control over frequency, amplitude, and modal content. The rig has been designed to evaluate the effect of curvature on the performance of duct liners such as are found in the aft fan bypass duct on a high bypass ratio aircraft engine. However, the design of the test rig is flexible to support investigation of fundamental duct noise propagation in large scale ducts with significant mean flow, validation of duct sound propagation codes, and development of adaptive and active noise control technologies.

\section{A. Test Rig Hardware}

The test duct, designated Curved Duct Test Rig is shown in Figure 2. It has been assembled in the Anechoic Noise Research Facility at NASA Langley Research Center. Air enters the duct from beneath the floor of the chamber into a vertical leg seen at the right of the figure. The duct is $0.762 \mathrm{~m} \mathrm{x} 0.762 \mathrm{~m}$ in cross-section. Air then enters an elbow to turn it $90^{\circ}$ to horizontal. The elbow contains 15 equally spaced airfoil-shape turning vanes whose function is to distribute the flow uniformly through the $90^{\circ}$ turn. Downstream of the elbow is the flow conditioning section that has slots to accommodate honeycomb and up to 5 wire mesh screens for flow straightening and turbulence reduction. The current configuration has 1 honeycomb and 1 wire mesh screen. The next section is a contraction section that reduces the duct size to the test section cross section of $0.152 \mathrm{~m} \times 0.381 \mathrm{~m}$. The source section, which contains the loudspeakers, is downstream of the contraction, and the upstream microphone array is next in the flow path. The test section is the next duct section. It can be seen in the figure adjacent to a hardwall calibration duct, and figure 3 is a close up view of the test section. The hardwall calibration duct is used for system checkout purposes. The downstream microphone array is used to assess sound reduction through the test section. The microphone array layout in the downstream microphone section is a replica of the upstream array layout. Downstream of the downstream microphone array duct section is a diffuser. The diffuser expands the flow cross section from $0.152 \mathrm{~m}$ x $0.381 \mathrm{~m}$ to $0.425 \mathrm{~m}$ x $0.381 \mathrm{~m}$ over a length of $1.753 \mathrm{~m}$ for an expansion angle of approximately $4.46^{\circ}$. The walls of the diffuser are lined with perforate behind which is acoustic foam whose depth and density vary axially. The intention of the design is two-fold. The small diffusion angle provides separation-free expansion of the flow and the acoustic wall treatment is intended to simulate a $\rho c$ termination. The diffuser was designed using ISO guidelines for design of an anechoic termination for a flow duct. ${ }^{30}$ 


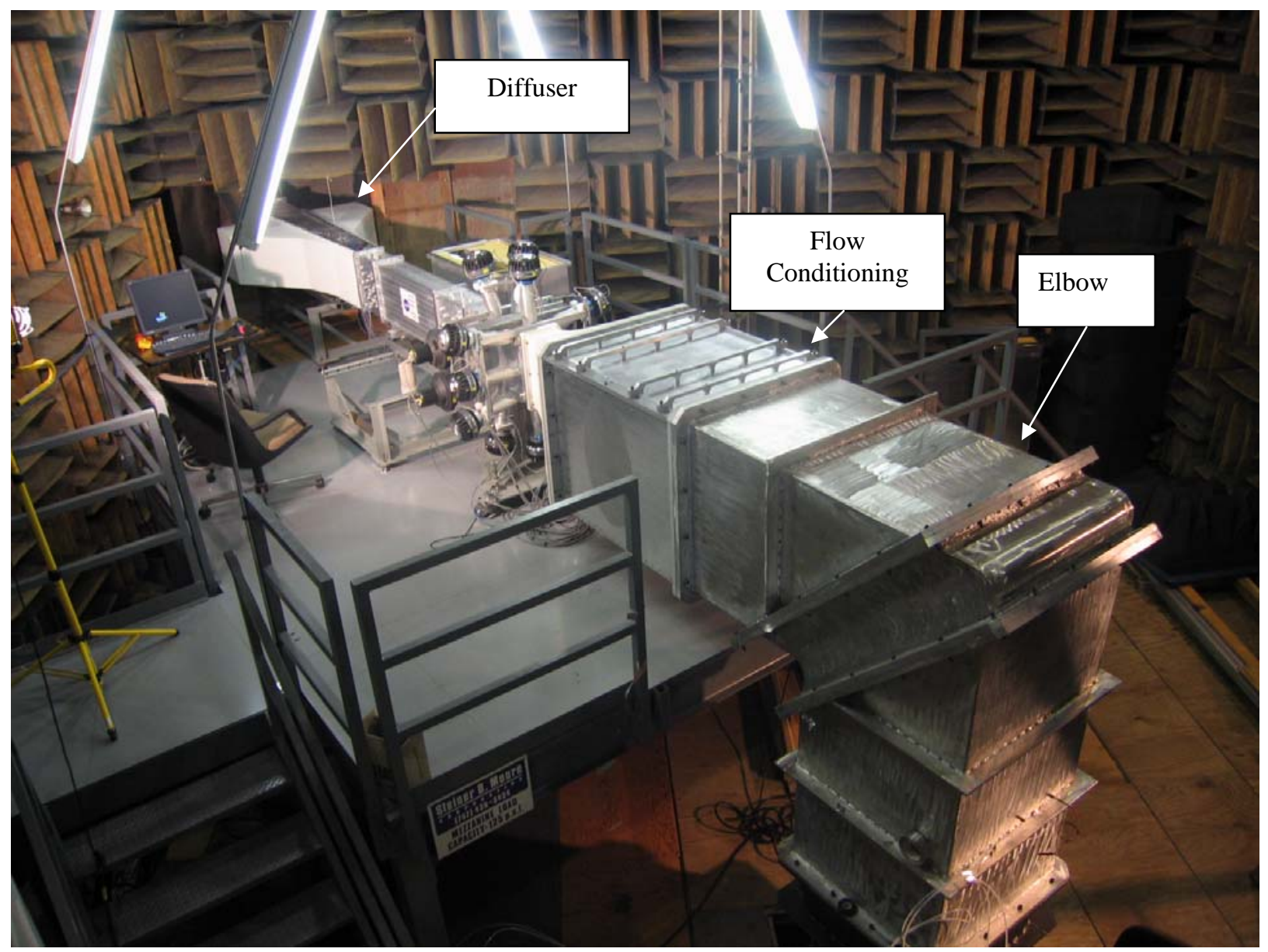

Figure 2: Curved Duct Test Rig in Anechoic Noise Research Facility.

The test section duct is shown in figure 3. It can also be seen in figure 2, located adjacent to the hardwall calibration duct. The top of the test section has been removed to reveal a liner sample that is being readied for evaluation. The liner sample is held in place by a support structure consisting of hard foam backing. The width, a, of the flow path is $0.152 \mathrm{~m}$ in this case. The flow path is straight through, however the flow path can be offset from inlet to discharge by as much as 1 duct width. The test section has been designed to accommodate a variety of duct liner types including locally reacting liners, bulk reacting liners, passive adaptive (Herschel-Quincke tubes) designs, active adaptive wall sections, and flow splitters.

\section{B. Test rig instrumentation}

Microphone arrays measure the sound field both upstream and downstream of the test section. Each array consists of $31 \mathrm{~B} \& \mathrm{~K}$ model 4951 piezo-ceramic microphones mounted with the sensing element flush with the inner surface of the duct wall. The optimizing procedure by which the microphone array layout was determined is discussed in section III-B, Microphone Locations. The sound signals pass through a B\&K model 2964 32-channel signal conditioner and then to a Precision Filters 6000-series low pass filter/amplifier. Data are recorded on a digital computer using National Instruments model 4472 Signal Conditioning unit with National Instruments model 4351 A/D converters. In addition to the acoustic data, the pressure and temperature in the duct are recorded in order to determine the air flow in the duct.

The magnitude and phase of signal for each loudspeaker are adjusted according to the method described in section III-A, Sound Control System. The signal is amplified by 16 Carver model TF-40 amplifiers and sound is introduced into the duct by 12 BMS model 4592 and 4 JBL model 2485J drivers. The drivers are connected to the duct by constant cross-sectional area transitions that go from the $50.8 \mathrm{~mm}$ diameter loudspeaker port to a slot in the duct wall of approximate dimension $95.25 \mathrm{~mm}$ x $19.05 \mathrm{~mm}$. These transitions are intended to vibration isolate the loudspeaker from the duct wall and to maximize sound energy 


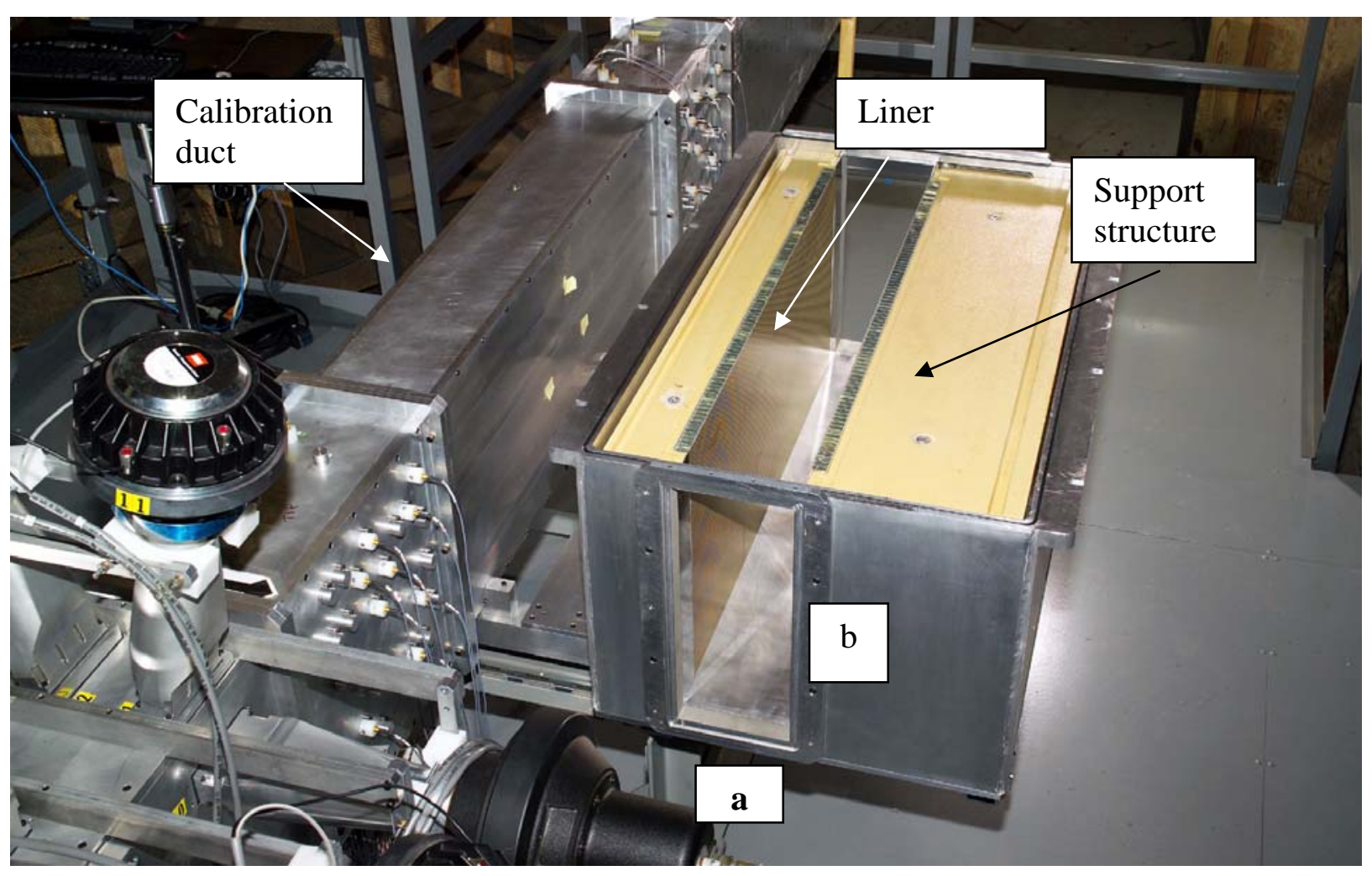

Figure 3. Curved Duct Test Rig test section (top removed) showing liner sample.

transfer from the loudspeaker to the duct interior. Sixteen loudspeakers are mounted in the duct walls as indicated in figures 2 and 3. The loudspeaker locations were chosen to couple to all the cut on duct modes across the frequency range of interest. It is expected that as high as order 2 mode can be generated on the short side of the duct, and 5-order mode on the long side.

\section{Results}

The test rig has been evaluated to assess its suitability for research use. The results presented here concentrate on those tests intended to demonstrate that the CDTR can be used to generate quality results.

\section{A. Sound Measurement System Performance Check}

The sound measurement equipment used in the CDTR are regularly calibrated against known standards by an independent organization outside the laboratory. Two procedures have been developed inhouse to ensure that the measurement system is functioning properly.

An end-to-end evaluation of the sound measurement system is performed after every major configuration change or whenever the need for a more complete function check is indicated. For this evaluation, each microphone is removed from its holder in the side of the duct and inserted into a B\&K type 4226 multi-frequency electromagnetic calibrator that has been modified to output a reference signal that is phase-locked with the calibration tone. The magnitude and phase response for each channel, including microphone, preamplifier, signal conditioner, and A/D are evaluated at frequencies encompassing the operating range of the CDTR. These response factors define the frequency-dependent sensitivities that are applied to the microphone voltage signals.

An in-situ functionality check is performed before every run sequence. A single loudspeaker is used to generate a tone in the duct, which is read at both arrays. Comparison of the microphone responses to a baseline response, which was measured at the same time as the end-to-end evaluation, determines whether each microphone channel remains within tolerance. 


\section{B. Vibration Analysis}

A simple series of vibration tests was performed to understand the structural-acoustic behavior of the duct and highlight frequency regions that should be avoided for liner testing. Four accelerometers were affixed to the sidewalls of the upstream and downstream microphone sections at locations adjacent to a microphone. Simultaneous measurements of the vibration response and acoustic response to broadband noise input from a loudspeaker were recorded and analyzed. Across the frequency range from 400 to $4500 \mathrm{~Hz}$, the rms acceleration was found to be less than $0.1 \mathrm{~g}$, while the SPL is greater than $80 \mathrm{~dB}$. Based on information provided by the microphone manufacturer, any vibration-induced microphone response due to these acceleration levels will be negligible relative to the sound level in the duct.

The vibration analysis did indicate, however, that the vibration of the wall of the calibration duct is much higher than that of either of the microphone sections. This is because the walls of the calibration section have a larger unstiffened area and are $2 / 3$ as thick as the microphone section walls. When broadband noise is introduced into the duct, it was found that the structural response couples with the sound in the duct at 400 , 550, 680, 740, and $810 \mathrm{~Hz}$. In the analyses reported in the next sections, these frequencies are avoided.

The vibration study indicates that it is necessary to analyze the structural vibration of all the liner samples to ensure that the structural response characteristics are kept separate from the acoustic evaluations.

\section{Control System Performance: Flow Configuration without Flow}

The data from the microphone arrays are processed to determine the mode structure of the sound waves in the duct at any frequency in the operating range using equation 6 . Since there are 31 microphones in each array, it is expected that data from the array can be decomposed into as many as 30 modes (15 incident and 15 reflected) with adequate resolution. Based on the number of microphones and of loudspeakers, the upper frequency limit of the operating range is $2400 \mathrm{~Hz}$. The first cross mode cuts on in the duct at approximately $450 \mathrm{~Hz}$. Based on the efficiency of the loudspeakers, a lower frequency limit was established at $300 \mathrm{~Hz}$.

A complete calibration and evaluation of the acoustic performance of the CDTR is underway. The results presented here are intended to highlight some of the control system's capabilities and limitations. The control system was evaluated with the calibration duct in place using tones generated at a series of frequencies and mode shapes. Table 1 shows the modes that the control system can be expected to generate, in the ideal case, in the $0.152 \mathrm{~m} \mathrm{x} .0381 \mathrm{~m}$ duct when operating without flow and at standard conditions.

TABLE 1: Cut on frequencies of modes in the $0.152 \mathrm{mx} 0.381 \mathrm{~m}$ duct without flow at standard conditions

\begin{tabular}{|c|c|c|c|}
\hline$m^{n}$ & 0 & 1 & 2 \\
\hline 0 & 0.00 & 1128.00 & 2256.00 \\
\hline 1 & 451.20 & 1214.89 & 2300.68 \\
\hline 2 & 902.40 & 1444.54 & 2429.79 \\
\hline 3 & 1353.60 & 1761.99 & \\
\hline 4 & 1804.80 & 2128.31 & \\
\hline 5 & 2256.00 & 2522.28 & \\
\hline
\end{tabular}

\section{Plane Wave Excitation}

One of the facilities to which the CDTR will be compared as part of its complete checkout is the Grazing Incidence Tube. ${ }^{30}$ This facility is recognized in industry for high-quality measurement of the acoustic properties of duct liner materials. The $50.8 \mathrm{~mm}$ x $50.8 \mathrm{~mm}$ cross section duct supports plane waves at frequencies up to $3300 \mathrm{~Hz}$. A series of experiments was conducted to assess the ability of the control system to generate exclusively a plane wave in the CDTR with an amplitude of $130 \mathrm{~dB}$, over a frequency range of $300 \mathrm{~Hz}$ to $2400 \mathrm{~Hz}$. At each test frequency, responses of the upstream and downstream microphone arrays were acquired; and, since the hardwalled calibration duct 
was in place, the modal amplitudes at both arrays should nominally be the same. The data presented here were analyzed using microphones from the downstream array, thus offering an independent assessment of the control system's performance.

Typical results, from $1000 \mathrm{~Hz}$, are shown in Figure 4, quantified in terms of amplitudes of cut on modes in the duct. The modes evaluated are listed in order of increasing m-order, corresponding to circumferential modes in a circular duct; and for each m-order then in increasing n-order, corresponding to radial modes in a circular duct. The blue bars in the figure show the amplitude of each cut on mode propagating in the downstream direction, also designated as the incident wave, while the red bars show the amplitude of each mode propagating upstream (reflected from the near-anechoic termination). The figure shows that the control system was able to generate a plane wave with amplitude of $130 \mathrm{~dB}$, while suppressing all other downstream-propagating modes by nearly $30 \mathrm{~dB}$. The next highest mode amplitude is the upstreampropagating plane wave, which occurs due to a reflection from the near-anechoic duct termination. The parameter defined on the plot is the Mode Amplitude Ratio, which is the ratio of the desired mode's amplitude to the next highest amplitude mode expressed in $\mathrm{dB}$. If the Mode Amplitude Ratio is greater than $10 \mathrm{~dB}$, the desired mode is considered to be dominant.

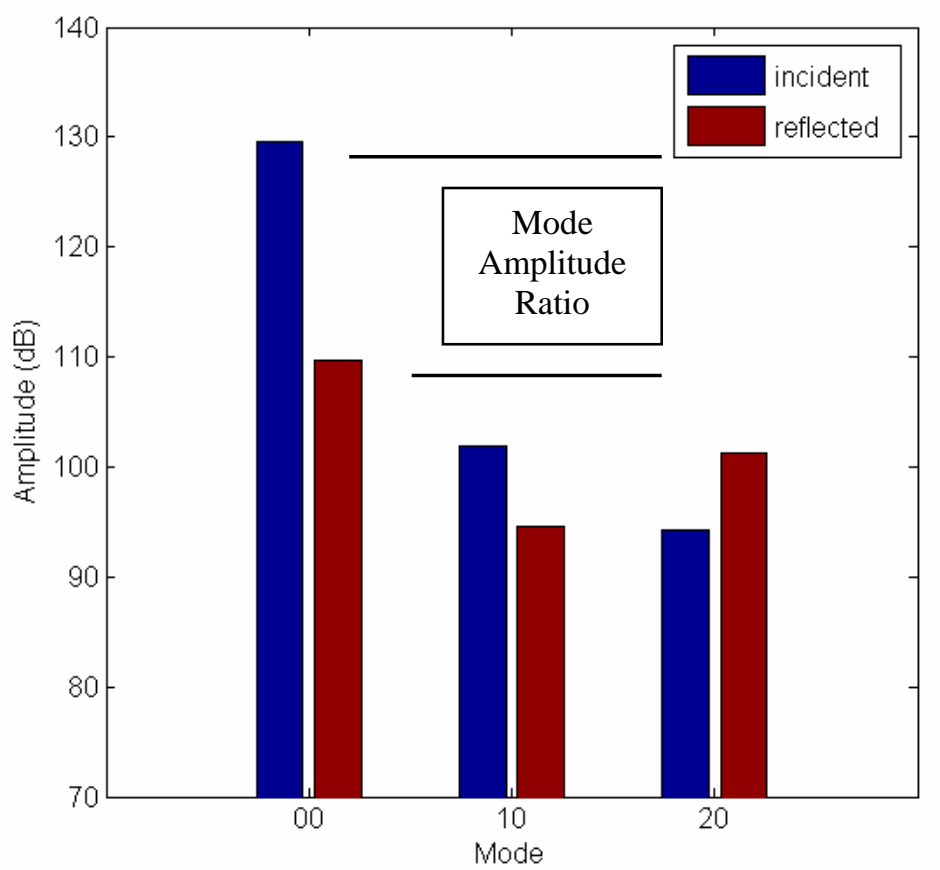

Figure 4. Modal decomposition of plane wave at $130 \mathrm{~dB}$ in the duct at $1000 \mathrm{~Hz}$, computed using downstream array measurement.

The mode amplitudes in Figure 4 can be used to reconstruct the measured pressures at the microphones, and these results are shown in Figure 5. The measured and reconstructed pressures agree to within $0.02 \mathrm{~dB}$ and 0.08 degrees, indicating the cuton modes constitute a sufficient set at this frequency. Deviation in Figure 5 from the desired uniform amplitude of $130 \mathrm{~dB}$, corresponding to a plane wave, is due to contributions from the other cuton modes, in the proportions shown in Figure 4. The results also confirm the number and placement of loudspeakers for generating a plane wave at this frequency.

The amplitude of the incident part of the plane wave from the mode analysis is evaluated over the frequency range from $300 \mathrm{~Hz}$ to $2400 \mathrm{~Hz}$ and is plotted in figure 6. The results show that the target mode amplitude of $130 \mathrm{~dB}$ is met to within $+/-1 \mathrm{~dB}$ up to $2000 \mathrm{~Hz}$ and drops off rapidly above $2300 \mathrm{~Hz}$.

The Mode Amplitude Ratio is evaluated over the same frequency range and is plotted in figure 7. The Mode Amplitude Ratio is always greater than zero, indicating that the incident plane wave is of highest amplitude, and generally, it is greater than $20 \mathrm{~dB}$, indicating that it is the dominant mode in the duct. Two exceptions are noted. The Mode Amplitude Ratio generally falls off at frequencies below $500 \mathrm{~Hz}$. This is felt to be due to the diffuser/termination at the end of the duct, which is not perfectly anechoic but reflects some 

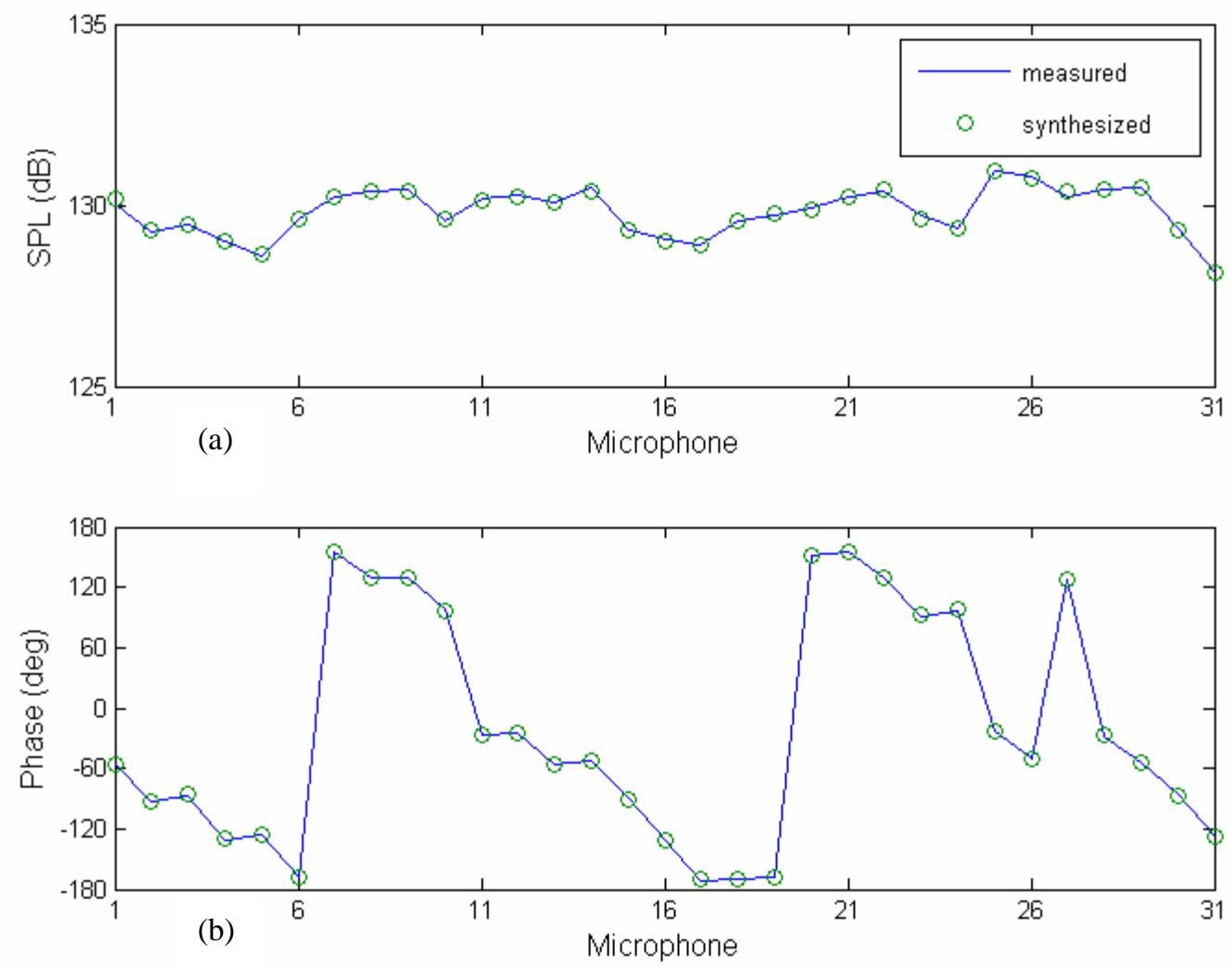

Figure 5. Comparison of measured to reconstructed sound level at microphones of downstream array based on mode distribution of plane wave data, 1000 Hz. (a) Amplitude, (b) Phase

acoustic energy back upstream in the duct at the lower frequencies. In the same way as the mode amplitude (figure 6), the Mode Amplitude Ratio falls off at high frequencies, above $2300 \mathrm{~Hz}$. The allowable voltage out of the controller is automatically limited to ensure that the loudspeakers are not over-driven. The signals to the loudspeakers were monitored during the experiment and it was found that the maximum voltage was reached at $2300 \mathrm{~Hz}$ and higher. This indicates the control system was not able to get enough acoustic energy into the duct to isolate the plane wave completely. Possible reasons for this difficulty at high frequency include an insufficient number of speakers, non-optimal speaker placement, or inefficient coupling between the speakers and the duct. Cutoff modes could also be complicating the control solution, since these modes represent additional degrees of freedom to be controlled.

It is noted that, even though the Mode Amplitude Ratio falls off at the upper and lower frequencies, it is greater than $10 \mathrm{~dB}$ at all frequencies except $2400 \mathrm{~Hz}$. Thus it is concluded that the wave is acceptably close to the selected plane wave.

\section{Effect of Evanescent Modes}

In an effort to study the influence of cutoff modes in the duct, varying numbers of cutoff modes were included in the mode decomposition, and the resulting pressure reconstruction error was computed. The rms error, $e$, expressed in percent, is calculated from:

$$
e=100 \sqrt{\sum_{i=1}^{N_{\text {mic }}} \frac{\left(p(i)_{\text {meas }}-p(i)_{\text {calc }}\right)^{2}}{p(i)_{\text {meas }}^{2}}}
$$




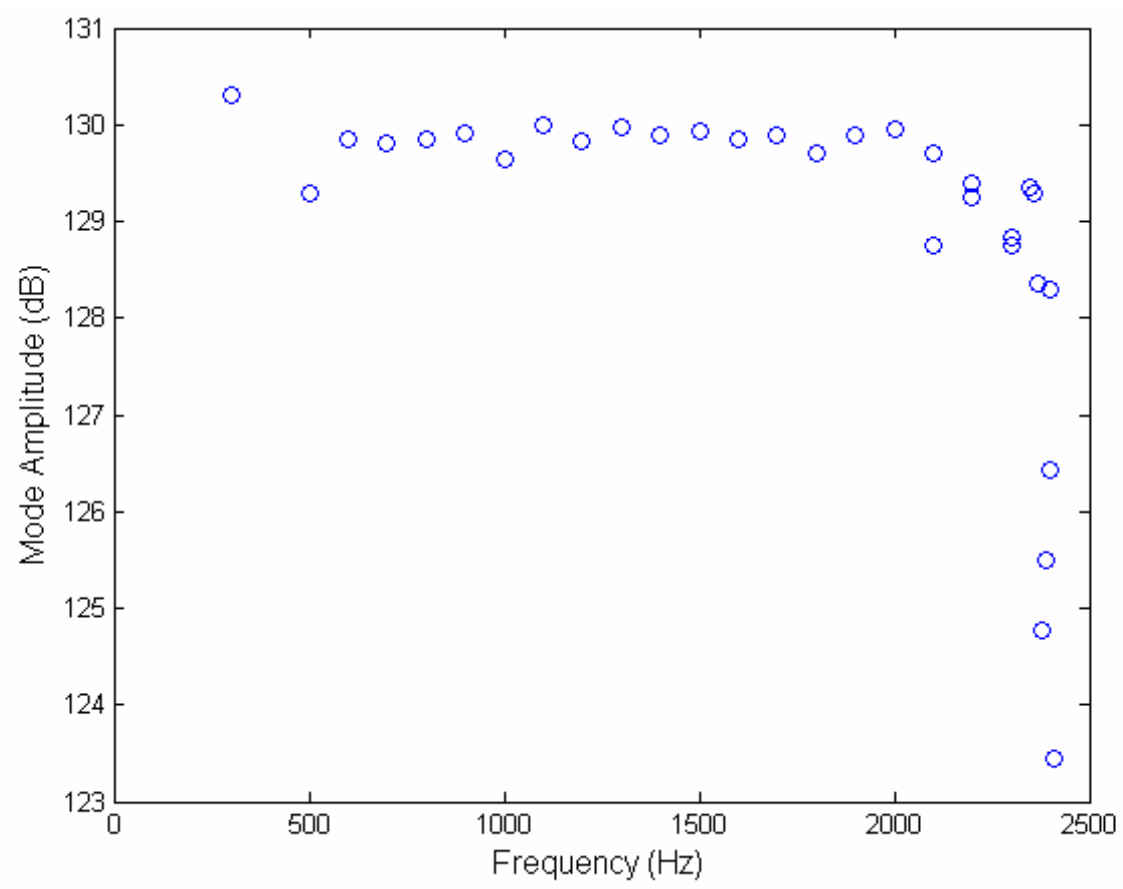

Figure 6. Amplitude of incident plane wave component from mode analysis of downstream microphone array for plane wave generation at $130 \mathrm{~dB}$ over operating frequency range in the duct.

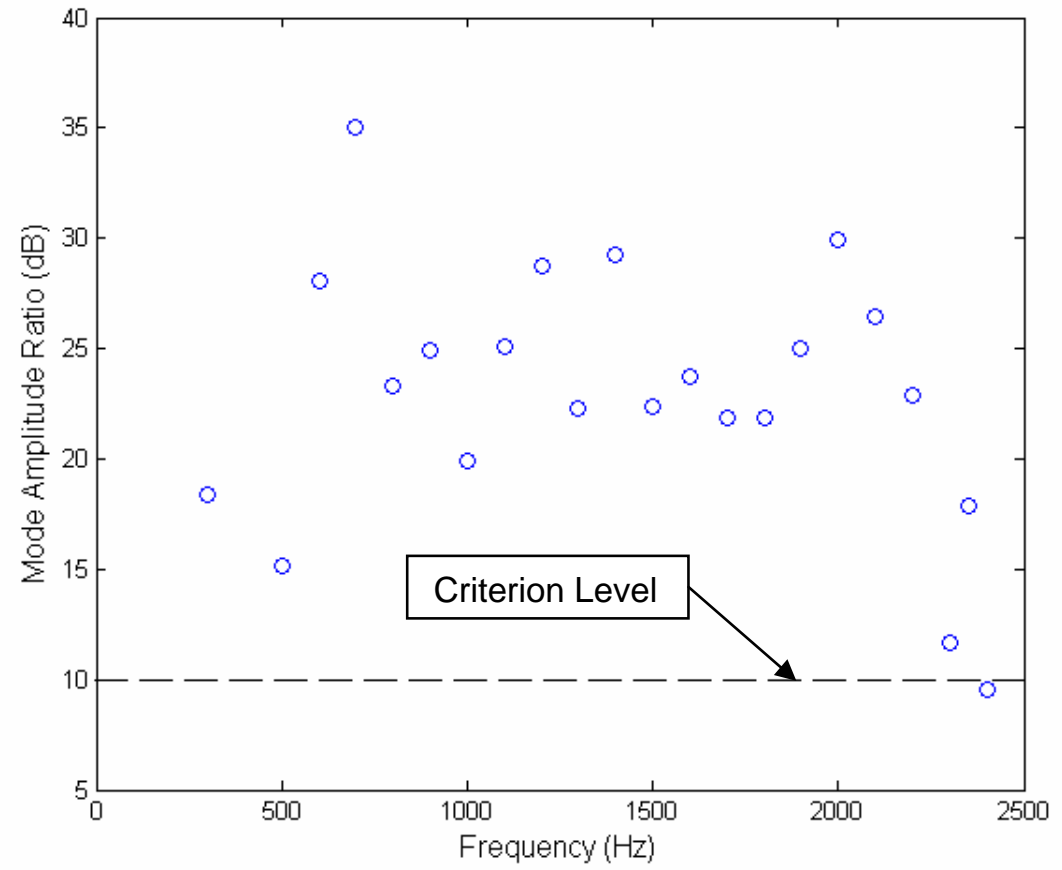

Figure 7. Mode Amplitude Ratio for plane wave generation at $130 \mathrm{~dB}$ over operating frequency range in the duct evaluated at the downstream array.

The rms error at the upstream array is plotted as a function of frequency for plane wave generation in figure $8 \mathrm{a}$ and the error at the downstream array is plotted in figure $8 \mathrm{~b}$. The error in the upstream array, which is close to the loudspeakers, peaks at $2200 \mathrm{~Hz}$. This frequency is just below the cut on of both the $(5,0)$ and the $(0,2)$ modes and these modes have not decayed sufficiently by the time they get to the upstream microphones. The reason for the spike at $1100 \mathrm{~Hz}$ in the downstream array is not readily apparent, although it 
is an indication of an impedance mismatch immediately downstream of the array, perhaps associated with the diffuser/termination.

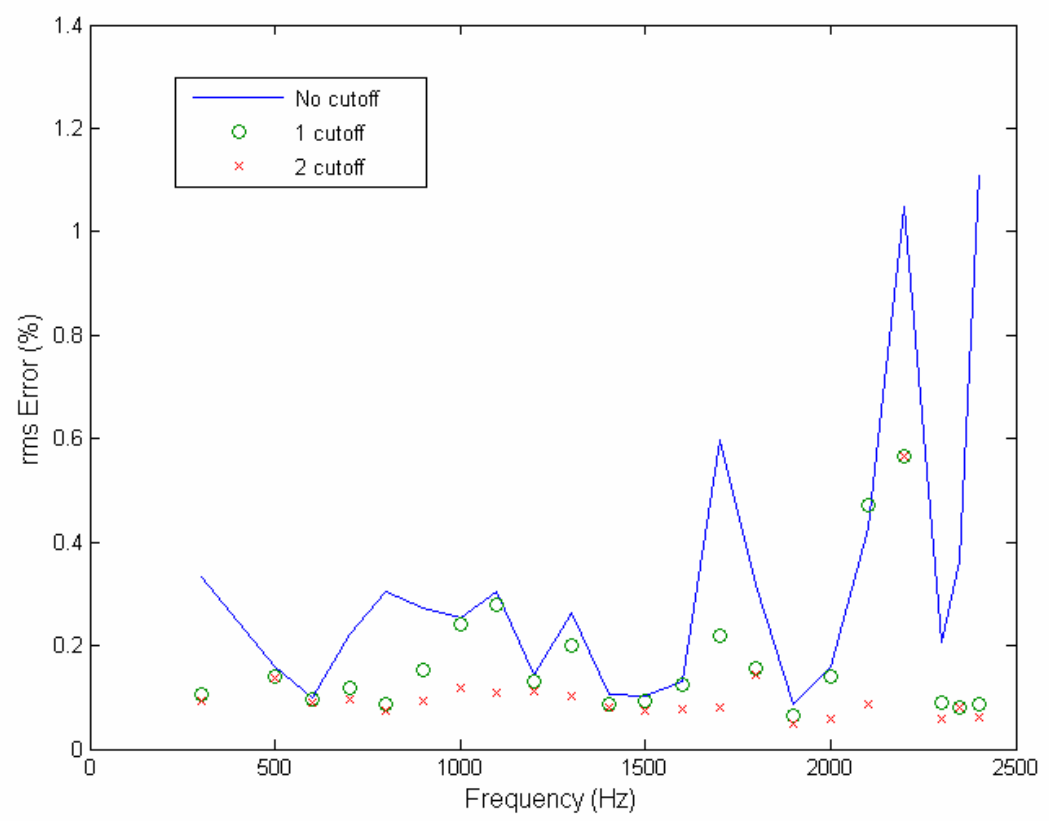

Figure 8a. Error of reconstructed sound level distribution at upstream microphones showing the effect of including evanescent modes in the calculation.

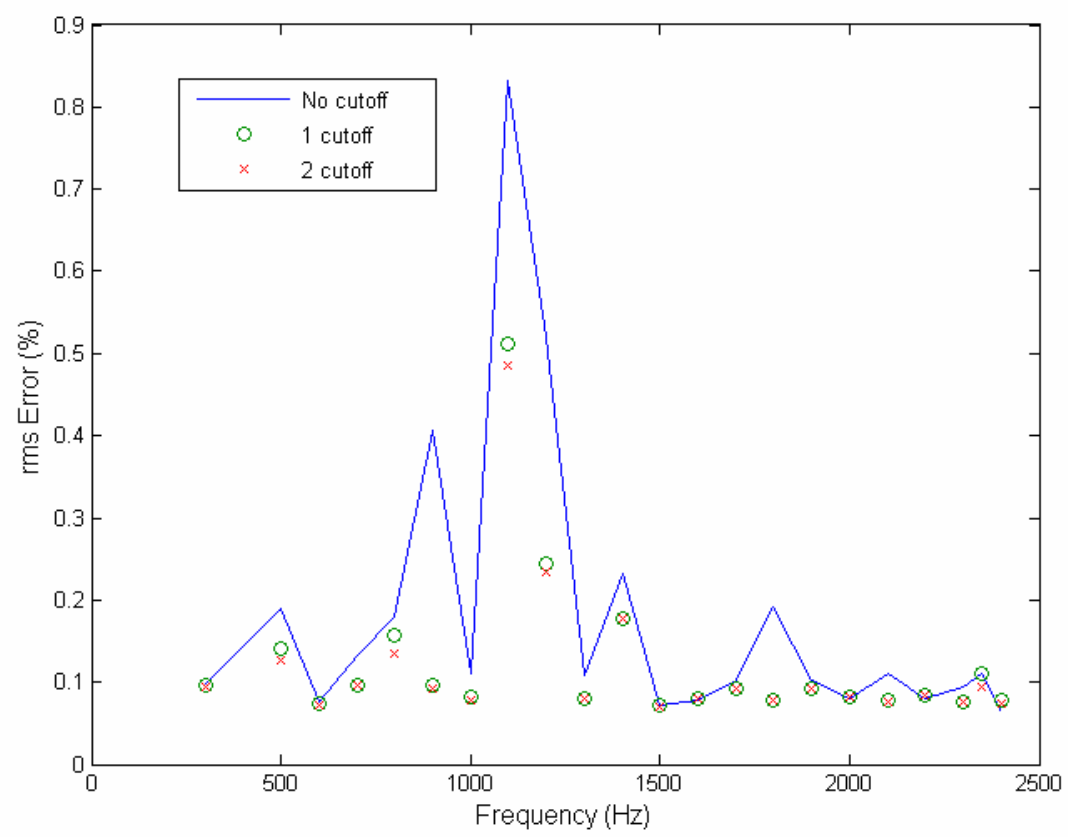

Figure 8b. Error of reconstructed sound level distribution at downstream microphones showing the effect of including evanescent modes in the calculation.

Incorporation of first 1 and then 2 cut-off modes in each calculation brings the error down, indicating that evanescent modes do have an effect on the sound level at the microphones. The error in any 
event is small, generally less than $1 \%$ of $63 \mathrm{~Pa}$ (at $130 \mathrm{~dB}$ ). This has not been an exhaustive error analysis but the results show that the issue of the effect of evanescent modes warrants further investigation.

\section{Generation of Higher Order Modes}

Preliminary evaluations of the control system generating higher order modes have been performed. Figure 9 shows the modal decomposition results when the target mode is the $(1,0)$ mode at $1000 \mathrm{~Hz}$. The incident component of the $(1,0)$ mode is highest of the 6 cut on modes, with a sound level of $130 \mathrm{~dB}$, which is $20 \mathrm{~dB}$ above the next highest mode.

Higher order modes were also targeted at $2350 \mathrm{~Hz}$. When the $(1,0)$ mode is specified at $130 \mathrm{~dB}$, the amplitude of the incident component of the $(1,0)$ mode is $129.8 \mathrm{~dB}$ and, from the mode decomposition shown in figure 10, the Mode Amplitude Ratio is $15.5 \mathrm{~dB}$. This is approximately equivalent to the plane wave results at $2350 \mathrm{~Hz}$, for which the Mode Amplitude Ratio is $17.9 \mathrm{~dB}$. It is expected to be a greater challenge to isolate higher order modes on the short side of the duct, because there are fewer loudspeakers on these walls. The results of this are shown in figure 11 for the $(1,1)$ mode and figure 12 for the $(1,2)$ mode. In both cases the target sound level of $130 \mathrm{~dB}$ is met and the Mode Amplitude Ratio is high, $24.1 \mathrm{~dB}$ for the $(1,1)$ and $25.9 \mathrm{~dB}$ for the $(1,2)$. These results for the higher

order modes are better than those for the plane wave and $(1,0)$ mode generation. It is felt that the reason the Mode Amplitude Ratio is lower for the plane wave and the $(1,0)$ mode is

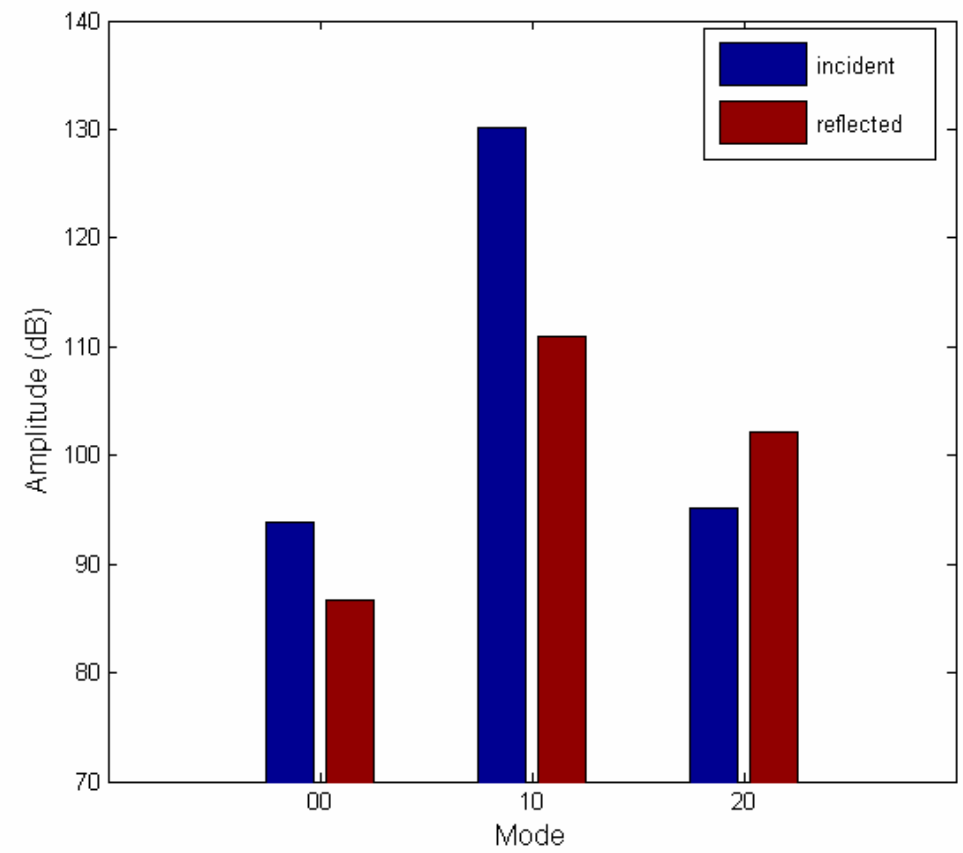

Figure 9. Mode distribution for generation of $(1,0)$ mode of $130 \mathrm{~dB}$ magnitude at $1000 \mathrm{~Hz}$ in the duct

that the loudspeakers expend too much energy trying to suppress the higher order modes. The controller actually becomes more efficient at the two higher order modes evaluated, which could arise from a better coupling of the loudspeakers with these modes resulting in less control effort to suppress lower order modes. A more complete investigation is currently being performed to quantify the ability of the controller and the sound generation and transduction hardware to isolate modes both with and without flow in the duct. 


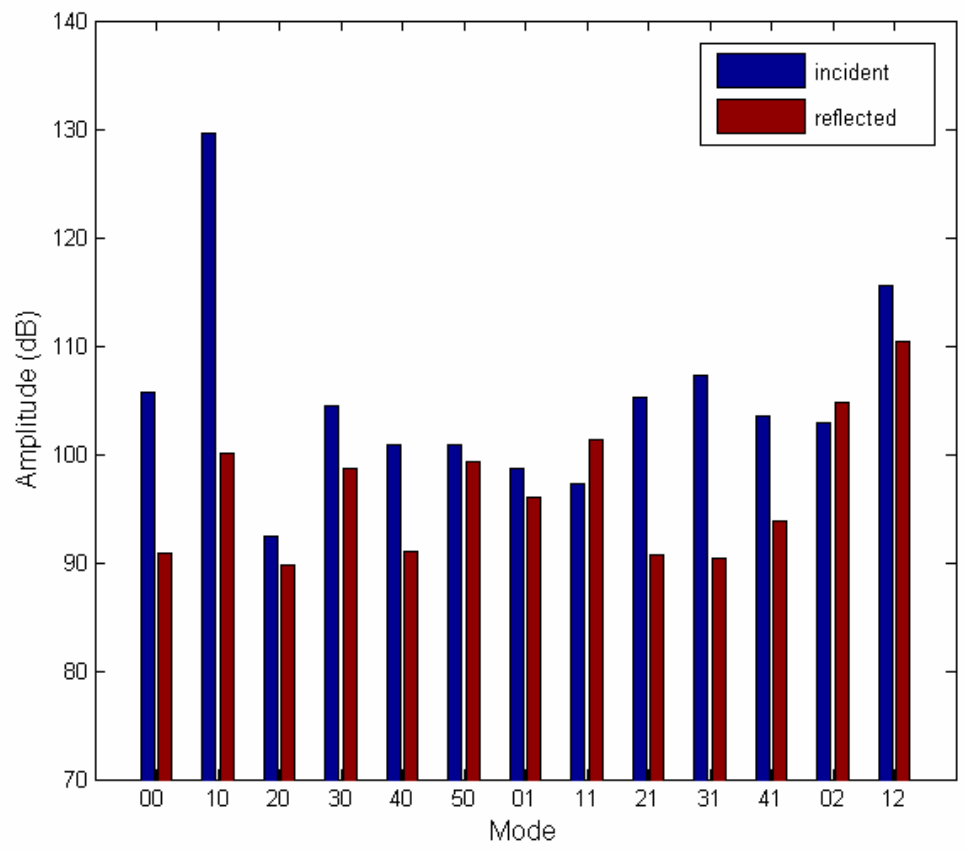

Figure 10. Mode distribution for generation of $(1,0)$ mode of $130 \mathrm{~dB}$ magnitude at $2350 \mathrm{~Hz}$ in the duct.

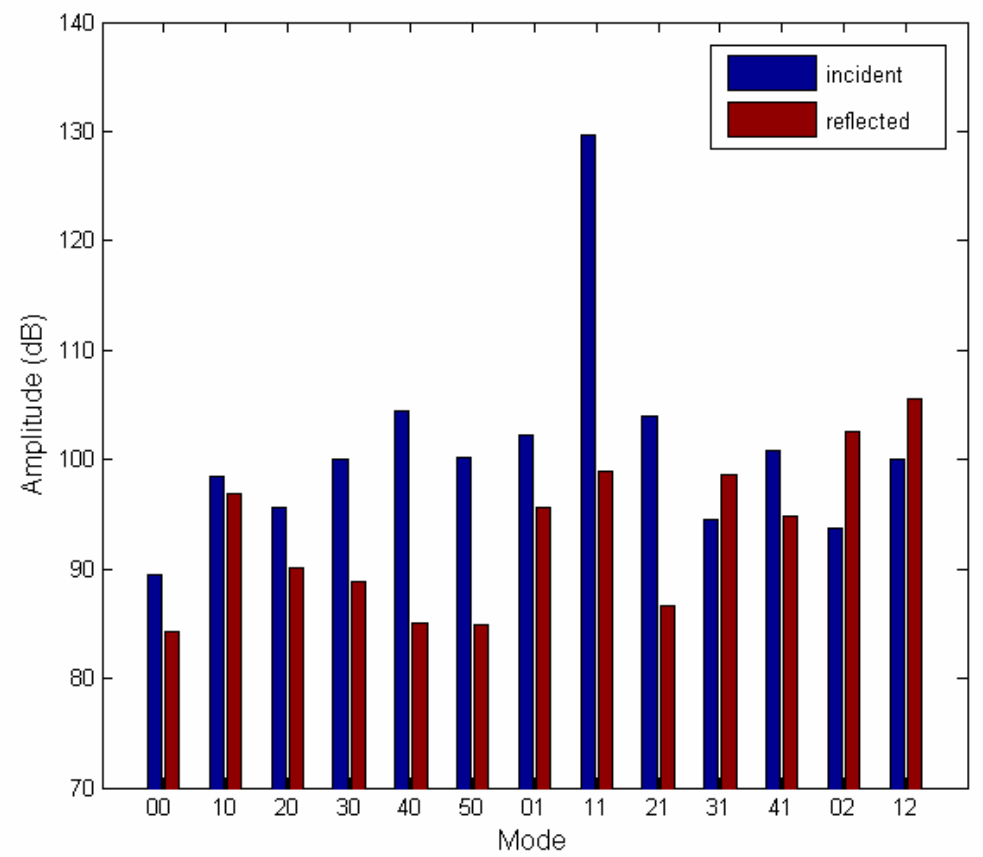

Figure 11. Mode distribution for generation of $(1,1)$ mode of $130 \mathrm{~dB}$ magnitude at $2350 \mathrm{~Hz}$ in the duct 


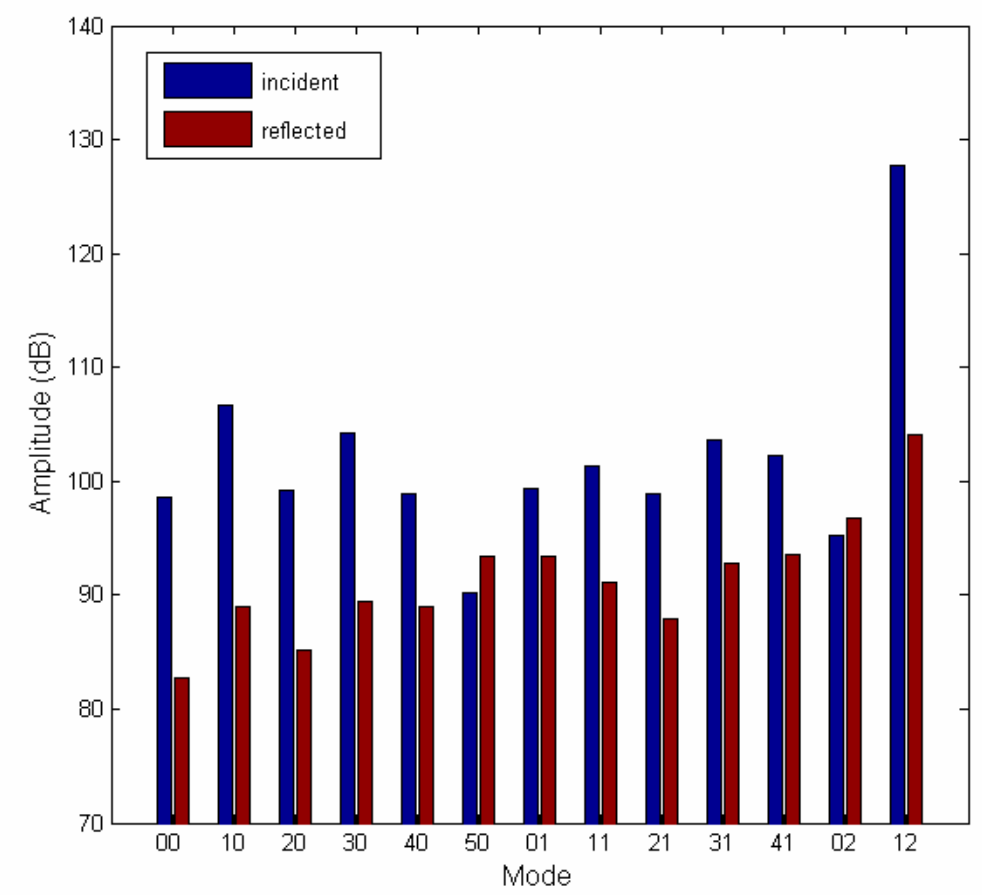

Figure 12. Mode distribution for generation of $(1,2)$ mode of $130 \mathrm{~dB}$ magnitude at $2350 \mathrm{~Hz}$ in the duct

\section{Summary}

The CDTR is a research test rig that has been developed to improve the understanding of the behavior of sound propagation in a duct in which higher order modes propagate. The CDTR will be used to evaluate the noise reduction of conventional and unconventional passive liners and active, adaptive noise control concepts. The rig can currently be used to investigate the effect of flow up to Mach 0.3. The test section can accommodate sidewall treatments with flow path straight through or curved between the inlet and the discharge. The purpose of this design feature is to allow investigation of the effect of flow path curvature on treatment performance, with the intention of taking advantage of curvature to optimize noise reduction performance. Test results from the experiments in the CDTR will be used to validate analytic models and to aid in their development.

Sound is generated in the CDTR by 16 loudspeakers distributed in two axial arrays. The loudspeaker locations were chosen to maximize acoustic coupling with all the cut on duct modes across the frequency range of interest. The loudspeaker array is used to generate sound in the duct at at user-specified amplitude, frequency, and mode shape. The amplitude and phase of the signals driving the loudspeakers are continuously updated by way of a multi-input multi-ouput feedforward control system that uses the aggregate error between the desired pressure distribution at an array of flush-mounted microphones and the measured distribution as the cost function. The purpose of the controller is to provide a known, controllable source which propagates sound in a specified mode while suppressing all other modes in the duct. Sound is measured by two arrays of side wall-mounted microphones, one upstream of the test section and the other downstream. The upstream array only is used in the control phase and both arrays are used in the data acquisition phase of an experiment. Each array consists of 31 laboratory-quality microphones and it is expected that as many as 30 modes (15 upstream propagating and 15 downstream propagating) can be resolved by each array. The duct is terminated by a diverging flow path that increases the flow area by 2.8 . The sidewalls of the diverging section are perforated and backed by acoustic material of variable density and depth. The design is intended to provide an anechoic termination to the duct.

A complete evaluation of the test rig is currently underway and preliminary analysis of the CDTR is reported in this paper. The structural vibration response of the microphone sections has been found to be small in comparison to the sound level in the duct, although a special duct used for calibration was found to respond to acoustic input at several structural resonant frequencies. This experiment points out the necessity to determine the vibrational characteristics of each acoustic treatment sample as well as the coupling between 
the vibrational and acoustic responses. The control system is found to be able to isolate plane waves in the duct over a range of frequencies from 500 to $2300 \mathrm{~Hz}$. The controler was not able to reach the target sound level or mode isolation for plane waves above $2300 \mathrm{~Hz}$. The plane wave is dominant in all cases tested and its amplitude is at least $10 \mathrm{~dB}$ higher than the next highest mode amplitude. The effect of including evanescent modes in the mode calculation is investigated. It is found that, particularly near cut on frequencies of higher order modes, inclusion of the up to two evanescent modes in the calculation reduces the root mean square error between the measured sound pressure distribution at the measurement microphones and the sound pressure that is calculated from the modal amplitudes. The error is small in any event, generally less than $1 \%$, but the issue of evanescent modes is felt to warrant further analysis. The control system is shown to isolate higher order modes successfully at frequencies in the middle of the operating range, $1000 \mathrm{~Hz}$, as well as near the upper end of the operating range, $2350 \mathrm{~Hz}$. The controller is demonstrated to isolate user-specified modes in both the vertical and horizontal axes of the duct. A more complete investigation will be performed to determine of the the limits of the controller and the sound generation and transduction hardware.

\section{Acknowledgements}

The authors wish to extend sincere appreciation to Mr. Brian Howerton of Lockheed-Martin for his contribution to the acquisition and assembly of the data acquisition and control systems as well as for data acquisition software development, and to Mr. Doug Weber of Swales Aerospace for his contribution to the design of the test rig hardware. The authors also wish to acknowledge the contributions of Ms. Christal Kellam of the Aerothermodynamics Support Section in the assembly of the test rig and continuing data collection support, and to thank Mr. Mike Jones and Dr. Richard Silcox of the Structural Acoustics Branch and Dr. Joe Posey of the Aeroacoustics Branch for their suggestions and encouragement throughout the development of this project.

\section{References}

1. Tyler, J.M. and Sofrin, T.G., "Axial Flow Compressor Noise Studies", SAE Transactions, vol. 70, 1962, pp 309-332

2. Woodward, RP and Balombin, JR, “Tone generation by rotor-downstream strut interaction”, AIAA paper 83-0767, 1983

3. Heidmann, MF, Saule, AV and McArdle, JG, "Analysis of radiation patterns of interaction tones generated by inlet rods in the JT15D engine”, AIAA paper 79-0581, 1979

4. Rice, E.J. and Heidman, M.F., "Modal Propagation Angles in a Cylindrical Duct with Flow and Their Relationship to Sound Radiation”, AIAA paper AIAA-79-0183, 1979

5. Thomas, R.H., Farassat, F., Clark, L.R., Gerhold, C.H., Kelly, J.J., and Becker, L.E., “A Mode Detection Method Using the Azimuthal Directivity of a Turbofan Model”, AIAA paper number 1999-1954, May, 1999

6. Sutliff, D., Konno, K., and Heidelberg, L., "Duct Mode Measurements on the TFE 732-60 Full Scale Engine”, AIAA paper AIAA-2002-2564, 2002

7. Gerhold, C.H., "Determination of Fan Inlet Duct Mode Structure Using In-duct Microphone Array Measurement”, presented at $141^{\text {st }}$ meeting of the Acoustical Society of America, June, 2001

8. Joppa, P.D., “An acoustic mode measurement technique”, AIAA paper 84-2337, 1984

9. Heidelberg, L.J., Rice, E.J., and Homyak, L., “Acoustic performance of inlet suppressors on an engine generating a single mode”, AIAA paper 81-1965, 1981

10. Silcox, R.J., "Experimental Investigation of Geometry and Flow Effects on Acoustic Radiation from Duct Inlets”, AIAA paper 83-28012, 1983.

11. Ville, J. M. and Silcox, R. J., "Experimental investigation of the radiation of sound from an unflanged duct and a bellmouth, including the flow effect”, NASA-TP-1697, Aug 1, 1980

12. Silcox, R.J. and Lester, H.C., "Sound Propagating Through a Variable Area Duct: Experiment and Theory”, AIAA paper AIAA-81-1967, 1981

13. Jones, M.G., Watson, W.R., Tracy, M.B., and Parrott, T.L., "Comparison of Two Waveguide Methods for Educing Liner Impedance in Grazing Flow,” AIAA Journal, Vol. 42, No. 2, 2004, pp.232-240.

14. Watson, W. R., “An evaluation of circumferentially segmented duct liners”, AIAA Paper 83-0732, 1983 
15. Parrott, T. L. and Watson, W. R., "Comparison of measured and calculated mode redistribution associated with spinning mode transmission through circumferentially segmented lined ducts", NASATM-84576, Mar 1, 1983

16. Remington, P., Sutliff, D., and Sommerfeldt, S., "Active Control of Low-Speed Fan Tonal Noise Using Actuators Mounted in Stator Vanes: Part 1 Control System Design and Implementation”, AIAA-20033190, May , 2003

17. Walker B., Hersh, A., Celano, J., and Rice,E., “Active Control of Low-Speed Fan Tonal Noise Using Actuators Mounted in Stator Vanes Part 2: Novel Error Sensing Concepts”, AIAA-2003-3191, May, 2003

18. Sutliff, D., Remington, P., and Walker B., “Active Control of Low-Speed Fan Tonal Noise Using Actuators Mounted in Stator Vanes: Part 3 Results”, AIAA-2003-3193, May, 2003

19. Thomas, R.H., Burdisso, R.A., and Lane, S.A., "A Time Average Active Controller for Turbofan Engine Fan Noise Reduction”, AIAA Journal of Aircraft, Vol.33, No.3, pp. 524-531, 1996.

20. Smith, J. P., Burdisso, R. A., and Fuller, C. R., "Experiments on the active control of inlet noise from a turbofan jet engine using multiple circumferential control arrays”, AIAA-1996-1792, May, 1996

21. Gerhold, C.H., “Active Control of Fan-Generated Tone Noise”, AIAA Journal, vol. 35, no. 1, pp 17-22, January, 1997

22. Palumbo, D. L., "An operations manual for the Spinning Mode Synthesizer in the Langley Aircraft Noise Reduction Laboratory”, NASA-CR-165698, Mar 1, 1981

23. Vaidya, P.G., "State of the Art in Duct Acoustics", AIAA paper 77-1279, Oct., 1977

24. Elliott, S.J., Stothers, I.M., and Nelson, P.A., “A Multiple Error LMS Algorithm and Its Application to the Active Control of Sound and Vibration." IEEE Transactions on Acoustics, Speech, and Signal Processing, Vol. ASSP-35(10), Oct. 1987, pp. 1423-1434.)

25. Haykin, S., “Adaptive Filter Theory, $3^{\text {rd }}$ ed.” Chapter 10, Prentice Hall, 1996

26. Elliott, S, "Signal Processing for Active Control,” Academic Press, 2001

27. Padula, S.L. and Kincaid, R.K., "Optimization strategies for sensor and actuator placement”. Technical Report TM-1999-209126, NASA, April 1999.

28. Strang. G., Linear Algebra and its Applications. Harcourt Brace Jovanovich, 1988.

29. Glover, F. and Laguna, M.,Tabu Search. Kluwer Academic Publishers, Boston, 1997.

30. International Standards Organization, number 5136:2003(E) “Acoustics - Determination of sound power radiated into a duct by fans and other air-moving devices - In-duct method"

31. Jones, M.G., Parrott, T.L., and Watson, W.R., "Comparison of Acoustic Impedance Eduction Techniques for Locally-Reacting Liners,” AIAA Paper 2003-3306, May, 2003. 